\title{
Iatrogenic Brachiocephalic Artery Trunk Perforation Successfully Treated with Percutaneous Implantation of Covered Stent
}

\author{
Antonio Rizza $^{1 *}$, Francesco Negro ${ }^{2}$, Alberto R. De Caterina ${ }^{3}$, Cataldo Palmieri ${ }^{4}$ \\ Sergio Berti $^{5}$ \\ ${ }^{1,3,4,5}$ Division of Interventional Cardiology, Fondazione Toscana Gabriele Monasterio, Massa, Italy. \\ ${ }^{2}$ Division of Cardiology of Pisa, Italy
}

\begin{tabular}{|c|c|}
\hline & BSTRACT \\
\hline $\begin{array}{l}\text { Keywords: } \\
\text { Percutaneous endovascular } \\
\text { repair, Radial access, } \\
\text { Vascular complications, } \\
\text { Brachiocephalic trunk } \\
\text { perforation }\end{array}$ & $\begin{array}{l}\text { Percutaneous coronary intervention through right radial artery access significantly reduces } \\
\text { vascular complications compared to femoral access-an 80-year-old woman presented with } \\
\text { non-ST segment elevation acute coronary syndromes (NSTE ACS). Coronary angiography } \\
\text { performed using right radial artery access showed left anterior descendent artery disease with } \\
\text { multiple stenoses, which was treated percutaneously. Ten minutes after the procedure, the } \\
\text { patient presented dyspnea, hypotension, neck edema, and jugular turgor. She was }\end{array}$ \\
\hline $\begin{array}{l}\text { Received } \\
17 \text { May } 2021 \\
\text { Received in revised form } \\
17 \text { May } 2021 \\
\text { Accepted } \\
17 \text { May } 2021 \\
\end{array}$ & $\begin{array}{l}\text { and vasopressors. Urgent computerized tomography showed brachiocephalic artery trunk } \\
\text { dissection and perforation with extravascular hemorrhage in the mediastinum and neck with } \\
\text { venous compression without any sign of aortic, carotid, or subclavian dissection. Two days } \\
\text { later, the percutaneous endovascular repair was performed, and a covered self-expanding } \\
\text { stent was successfully positioned in the brachiocephalic trunk, sealing the perforation and } \\
\text { treating the dissection. The patient progressively recovered and was discharged for } \\
\text { rehabilitation. We provided the first report of a brachiocephalic trunk perforation using a }\end{array}$ \\
\hline${ }^{*} \mathrm{Co}$ & $\begin{array}{l}\text { radial approach, causing mediastinal and neck hematoma treated with percutaneous } \\
\text { endovascular repair showing that vascular complications can be successfully treated } \\
\text { percutaneously if be performed by an experienced team. }\end{array}$ \\
\hline
\end{tabular}

CCIKD Publishing

Percutaneous coronary intervention (PCI) through right radial artery access represents the first choice because it significantly reduces vascular complications compared with femoral artery access [1]. However, the complicated anatomic angulations between right subclavian artery, 
brachiocephalic trunk, and aorta may result in difficulties in advancing the catheter leading to vascular complications.

Here we are presenting a case of brachiocephalic artery dissection, and perforation with neck and mediastinal hematoma following PCI through right radial access successfully treated with percutaneous implantation of a covered stent.

\section{Case Report}

An 80-year-old woman presented to our department with new-onset chest pain irradiating to the left arm and dyspnea. A diagnosis of acute coronary syndrome without ST-segment elevation was made, and the patient was treated with aspirin, clopidogrel, nitroglycerin, and urgent coronary angiography was also performed. Coronary angiography, performed using right radial artery access, showed left anterior descendent artery (LAD) disease with three significant stenoses located on proximal, medial and distal tract of the vessel. LAD revascularization with PCI and implantation of 5 zotarolimus-eluting stents was successfully performed. Ten minutes after the end of the procedure, while still in the cath lab, the patient started complaining of dyspnoea associated with cyanosis, hypotension, jugular vein turgor, and neck edema, and laryngeal stridor. The patient was immediately intubated and treated with invasive ventilation, intravenous corticosteroids, anti-histaminic and adrenaline with partial amelioration. Urgent computerized tomography (CT) with contrast showed brachiocephalic artery trunk perforation associated with extravascular hemorrhage of the mediastinum and neck with venous compression (Figure 1A and B). There was no sign of aortic, carotid, or subclavian dissection or cerebral hemorrhage. The patient was transferred to the intensive care unit and treated with vasopressors, fluid expansion, blood and plasma transfusions, and protamine infusion. During the following hours, the patient's hemodynamics improved, and vasopressors were reduced, where there was no need for further blood transfusion with stable hemoglobin values at $10 \mathrm{~g} / \mathrm{dl}$.

This was discussed by our team, consisting of heart surgeons, vascular surgeons, cardiologists, and anesthesiologists. Regarding the high risk of surgery and the patient's clinical stability without severe anemia, immediate surgery was ruled out .After 24 hours, a new CT exam was performed, confirming the presence of brachiocephalic artery trunk fissure without signs of active hemorrhage. There was also a reduction of the extravascular hematoma on the neck and mediastinum. The case was discussed again in the heart team, and a percutaneous endovascular repair was performed after the surgeons confirmed that the risk-benefit ratio was too high to consent to open surgery.

Following general anesthesia, a left femoral arterial access was taken, and a $6 \mathrm{~F}$ sheath was positioned. The selective angiography of the brachiocephalic artery trunk confirmed the fissure just before the origin of the carotid and subclavian artery (Figure 1C; Supplementary Video). Therefore, a 0,035 smooth guidewire was advanced into the right common carotid artery under angiographic guidance and a covered self-expanding stent (Advanta 10x38 mm) was positioned in the brachiocephalic trunk. Post-dilatation of the distal edge of the stent was performed using a $12 \mathrm{~mm}$ balloon sealing the fissure. Final angiography showed a normally positioned stent with complete sealing of the fissure and patency of the common carotid and subclavian artery (Figure 1D). The total procedure time was 1 hour. After the procedure, the patient progressively recovered and was discharged for rehabilitation. 


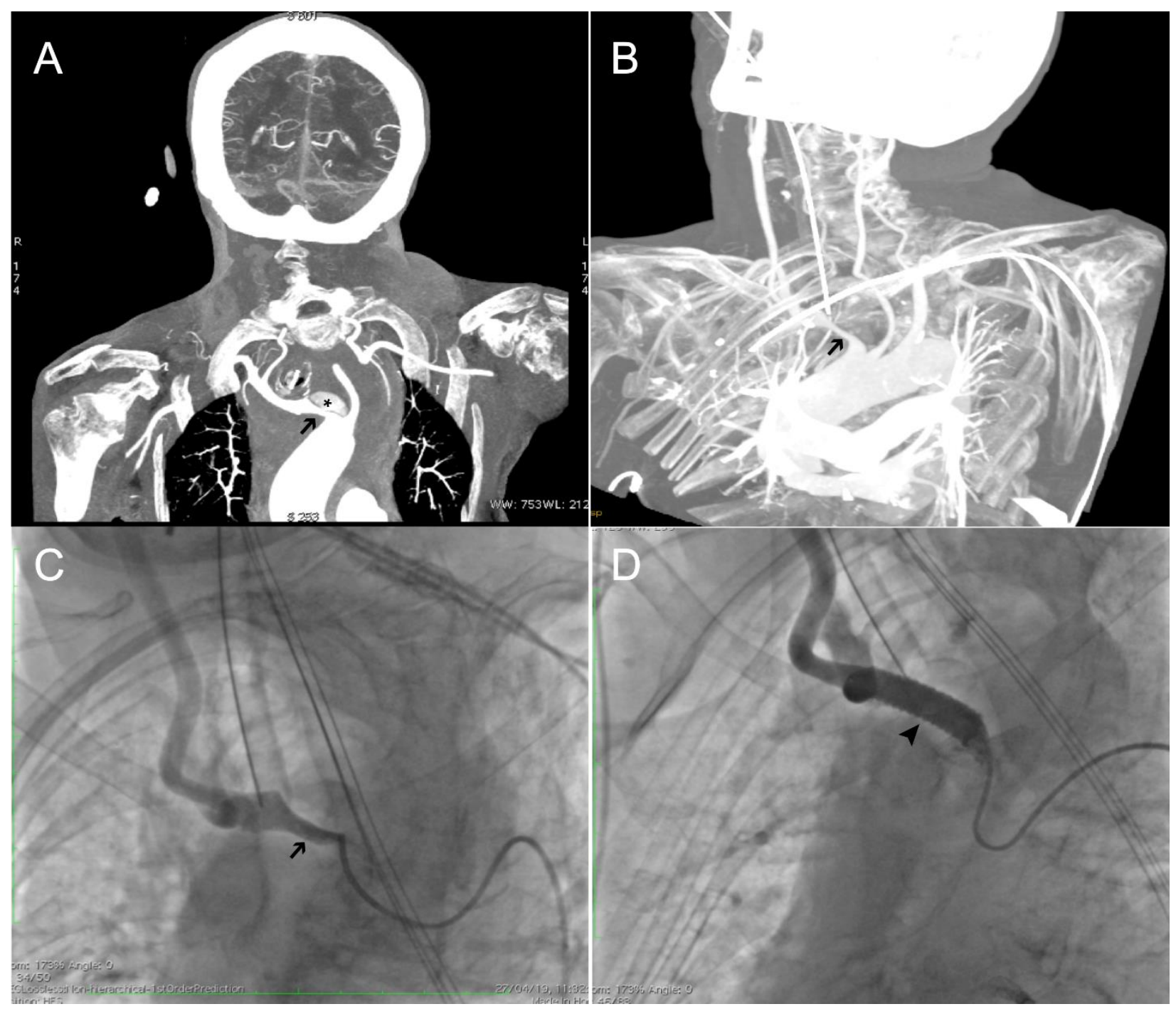

Figure 1. Computerized tomography scan showing brachiocephalic trunk artery dissection $(\rightarrow)$ with extravascular contrast leakage (*) (Panel A, B); Angiographic images of the dissection before (Panel C) and after (Panel D) deployment of a covered self-expanding stent $(\boldsymbol{>})$.

\section{Discussion}

In this case, we are reporting a rare case of brachiocephalic trunk perforation during PCI through the right radial approach, where the patient was successfully treated with percutaneous implantation of a covered stent.

Radial approach is the first choice for PCI when it is capable of reducing vascular complications compared to the femoral approach [1]. Different studies and a recent metanalysis have shown that the radial artery approach for PCI reduces short-term Major Adverse Cardiac Events, bleeding, and access site complications [2]. Furthermore, it is capable of improving patient's quality of life after the procedure and reducing the duration of hospitalization [3]. However, a radial access approach is not free of complications.

While radial artery spasm is a common event, major vascular complications such as perforations, pseudoaneurysm, or dissection of brachial, subclavian, brachiocephalic artery, or aorta have been reported but are extremely rare [4-8]. The complex anatomic angulations between the right subclavian artery, brachiocephalic trunk and aorta may result in difficulties in manipulating the catheter thus leading to vascular complications. Although the vascular anatomy was apparently normal in our case, during its advancement, the catheter may have caused the erosion and ulceration of a soft plaque in the aortic arch proximal to the origin of the 
brachiocephalic artery, leading initially to the dissection and perforation of the brachiocephalic artery.

To the best of our knowledge, this is the first case of a brachiocephalic trunk dissection and perforation by applying radial approach, causing mediastinal and neck hematoma. While most vascular complications were treated conservatively or by surgery. Regarding the high surgical risk of the patient, we successfully treated this complication by percutaneous implantation of a covered stent.

\section{Conclusion}

Major vascular complications of PCI through radial artery access are rare but possible; thus, prompt detection and treatment are extremely important to prevent any fatal outcome. Vascular perforations can be successfully treated with percutaneous implantations of covered stents if performed by an experienced team.

\section{References}

[1] Mason PJ, Shah B, Tamis-Holland JE, Bittl JA, Cohen MG, Safirstein J, Drachman DE, Valle JA, Rhodes D, Gilchrist IC. An Update on Radial Artery Access and Best Practices for Transradial Coronary Angiography and Intervention in Acute Coronary Syndrome: A Scientific Statement From the American Heart Association. Circ Cardiovasc Interv 2018;11(9):e000035.

[2] Kolkailah AA, Alreshq RS, Muhammed AM, Zahran ME, Anas El-Wegoud M, Nabhan AF. Transradial versus transfemoral approach for diagnostic coronary angiography and percutaneous coronary intervention in people with coronary artery disease. Cochrane Database Syst Rev 2018;4:Cd012318.

[3] Cooper CJ, El-Shiekh RA, Cohen DJ, Blaesing L, Burket MW, Basu A, Moore JA. Effect of transradial access on quality of life and cost of cardiac catheterization: A randomized comparison. Am Heart J 1999;138(3 Pt 1):430-6.

[4] Ghori MA, Al Zubaidi A, Khwaja A. Thyrocervical trunk perforation: A rare vascular complication during cardiac intervention through right radial approach: A case report and literature review. J Saudi Heart Assoc 2019;31(3):121-4.

[5] Jao YTFN, Chen Y, Fang C-C, Wang S-P. Mediastinal and neck hematoma after cardiac catheterization. Catheterization and Cardiovascular Interventions 2003;58(4):467-72.

[6] Merkle J, Hohmann C, Sabashnikov A, Wahlers T, Wippermann J. Central Vascular Complications Following Elective Catheterization Using Transradial Percutaneous Coronary Intervention. J Investig Med High Impact Case Rep 2017;5(1):2324709617698717.

[7] Shroff A, Siddiqui S, Burg A, Singla I. Identification and management of complications of transradial procedures. Curr Cardiol Rep 2013;15(4):350.

[8] Villanueva-Benito I, Solla-Ruiz I, Rodriguez-Calveiro R, Maciñeiras-Montero JL, Rodriguez-Paz CM, Ortiz-Saez A. Iatrogenic Subclavian Artery Pseudoaneurysm Complicating a Transradial Percutaneous Coronary Intervention. JACC: Cardiovascular Interventions 2012;5(3):360-1. 